Evaluation and comparison of type I tympanoplasty efficacy and histopathological changes to the tympanic membrane in dry and wet ear: a prospective study

\section{First letter}

Dear Editors,

We would like to address the manuscript titled 'Evaluation and comparison of type I tympanoplasty efficacy and histopathological changes to the tympanic membrane in dry and wet ear: a prospective study' by Shankar et al. ${ }^{1}$

Their work is excellent and expands the indications for myringoplasty for chronic tympanic membrane perforation, and should shorten the waiting time for surgery in patients with a chronic tympanic membrane perforation. However, we believe that two points need to be clarified.

First, the inclusion criteria included patients with history of discharge for at least six weeks, but the authors did not describe the degree or properties of the discharge in detail. Some studies have shown that a moist middle-ear condition without purulent discharge does not affect eardrum healing; in fact, it can accelerate eardrum healing. ${ }^{2-6}$ In comparison, an excessively wet environment adversely affects eardrum healing, especially in patients with purulent discharge. ${ }^{7}$ Studies have suggested that excess moisture in the wound bed impairs the healing process, leading to periwound maceration. ${ }^{8,9}$ If the excess moisture is left unchecked, healing can be impeded, and there may be subsequent breakdown and further deterioration of the wound bed. Therefore, we believe that the authors should clearly describe the degree and properties of the discharge to help the reader select patients.

Second, the authors did not describe in the Methods section of the article whether the sclerotic plaques on the residual eardrum need to be removed. The sclerotic plaques associated with chronic tympanic membrane perforation are an important factor affecting eardrum healing. Some studies of tympanoplasty for chronic tympanic membrane perforation found that excision of the sclerotic plaques improved the success rate. ${ }^{10,11}$ In addition, two studies of fibroblast growth factor-2 for traumatic and chronic tympanic membrane perforation proved that residual tympanic membrane calcification was a significant risk factor for non-healing of tympanic membrane perforation. ${ }^{12,13}$ The authors of a study of spontaneous healing in a large sample of traumatic tympanic membrane perforation cases suggested that pre-existing sclerotic plaques were the main cause of healing failure. ${ }^{4}$ Therefore, the paper would have been better if it had compared the success rates among tympanic membrane perforation patients with and without sclerotic plaque.

Z-C LOU

Department of Otorhinolaryngology, Affiliated YiWu Hospital of Wenzhou Medical University, Zhejiang, China

\section{References}

1 Shankar R, Virk RS, Gupta K, Gupta AK, Bal A, Bansal S. Evaluation and comparison of type I tympanoplasty efficacy and histopathological changes to the tympanic membrane in dry and wet ear: a prospective study. J Laryngol Otol 2015; 129:945-9

\section{LETTERS TO THE EDITORS}

2 Lou Z, Tang Y, Xiao J. The effect of ofloxacin otic drops on the regeneration of human traumatic tympanic membrane perforations. Clin Otolaryngol 2015. Epub 2015 Oct 14

3 Lou Z, Wang Y, Su K. Comparison of the healing mechanisms of human dry and endogenous wet traumatic eardrum perforations. Eur Arch Otorhinolaryngol 2014;271:2153-7

4 Lou ZC, Tang YM, Yang J. A prospective study evaluating spontaneous healing of aetiology, size and type-different groups of traumatic tympanic membrane perforation. Clin Otolaryngol 2011;36:450-60

5 Ozturk K, Yaman H, Cihat Avunduk M, Arbag H, Keles B, Uyar Y. Effectiveness of MeroGel hyaluronic acid on tympanic membrane perforations. Acta Otolaryngol 2006;126:1158-63

6 Caylan R, Titiz A, Falcioni M, De Donato G, Russo A, Taibah A et al. Myringoplasty in children: factors influencing surgical outcome. Otolaryngol Head Neck Surg 1998;118:709-13

7 Griffin WL Jr. A retrospective study of traumatic tympanic membrane perforations in a clinical practice. Laryngoscope 1979;89(2 Pt 1):261-82

8 Schultz GS, Sibbald RG, Falanga V, Ayello EA, Dowsett C, Harding K et al. Wound bed preparation: a systematic approach to wound management. Wound Repair Regen 2003;11(suppl 1): $\mathrm{S} 1-28$

9 Dowsett C, Ayello E. TIME principles of chronic wound bed preparation and treatment. Br J Nurs 2004;13:S16-23

10 Migirov L, Volkov A. Influence of coexisting myringosclerosis on myringoplasty outcomes in children. J Laryngol Otol 2009; 123:969-72

11 Aslan H, Katilmiş H, Oztürkcan S, Ilknur AE, Başoğlu S Tympanosclerosis and our surgical results. Eur Arch Otorhinolaryngol 2010;267:673-7

12 Hakuba N, Hato N, Okada M, Mise K, Gyo K. Preoperative factors affecting tympanic membrane regeneration therapy using an atelocollagen and basic fibroblast growth factor. JAMA Otolaryngol Head Neck Surg 2015;141:60-6

13 Lou Z, Yang J, Tang Y, Xiao J. Risk factors affecting human traumatic tympanic membrane perforation regeneration therapy using fibroblast growth factor-2. Growth Factors 2015;33: 410-18

The Journal of Laryngology \& Otology (2016), 130, 412-414. (c) JLO (1984) Limited, 2016 doi:10.1017/S0022215116000797

\section{Authors' reply}

Dear Editors,

We are glad to hear about the interest in our work titled 'Evaluation and comparison of type I tympanoplasty efficacy and histopathological changes to the tympanic membrane in dry and wet ear: a prospective study'. We would like to thank Dr Zhengcai Lou for reading our paper in depth. We have gone through the author's queries in detail.

Firstly, Dr Lou raised the question of whether the degree and nature of the ear discharge had any bearing on the healing results following tympanoplasty. In our study (as mentioned in the article), of the 35 patients with wet ear, 28 patients had mucoid discharge and 7 patients had mucopurulent discharge at the time of surgery. ${ }^{1}$ On subsequent evaluation of the success of graft uptake between the two types of discharge, no statistically significant difference in success rate was found $(p=0.526)$ (Table I). Similarly, no difference in the graft uptake rate was found when the degree of the discharge was compared.

Similar results have been shown by other authors. For example, a prospective audit study by Kotecha et al., which reviewed 1070 individuals, showed that patients 